\title{
A prospective study to evaluate access to elective surgical services in a urology unit of Sri Lanka
}

\author{
A.L.A.M.C. Ambegoda ${ }^{1}$, W.A.S. Weligamage ${ }^{1}$, M.C.M. Ishak ${ }^{1}$, U. Gobi ${ }^{1}$, Swarna Suvendiran ${ }^{1}$, Shinthuja \\ Mahadeva $^{1}$, P.K.B. Mahesh ${ }^{2}$, Malaka D Jayawardene ${ }^{1}$, Anuruddha M Abeygunasekera ${ }^{1}$ \\ ${ }^{1}$ Urology Unit, Colombo South Teaching Hospital, Sri Lanka \\ ${ }^{2}$ Office of Regional Director of Health Services of Colombo, Sri Lanka
}

Key words: Urological surgery; waiting list; equity; quality of care

\section{Abstract \\ Introduction}

One of the core indicators of monitoring universal access to safe, affordable surgical care is access to timely, essential surgery. Analysing the waiting time for elective operations is one way to determine access to surgical services in a country. Aims of this study were to determine the access to surgical services in a urology unit of Sri Lanka by analysing waiting time for elective surgical operations and to determine whether waiting time is related to income categories and social classes.

\section{Methodology}

All patients undergoing surgery (excluding emergency and elective minor surgery) at a urology unit between 01.01.2016 to 30.04.2017 were included in the study. The income groups were categorised according to the household income and receipt of Samurdhi benefit. Waiting time was the period between the day the decision was taken for surgery and the day of surgery.

\section{Results}

A total of 1079 patients had complete data and 845 (78.3\%) were men. Median waiting time for surgery was 40 days. Eighty nine $(8.2 \%)$ were Samurdhi beneficiaries and their median waiting time was 48 days. Two hundred and nineteen (20.3\%) operations were done for malignancies and the median waiting time was 20 days. Median waiting time for TURP and renal stone surgery were 55 and 125 days respectively. One hundred and seventy $(15.8 \%)$ patients had their operations postponed at least once. Survival analysis showed that there is no statistically significant difference between the waiting time with income levels $(\mathrm{p}=0.38)$ and recipient status of Samurdhi $(\mathrm{p}=0.29)$.

\footnotetext{
Correspondence: A.L.A.M.C. Ambegoda

E-mail: mcambegoda@yahoo.co.uk

Received: 25-02-2018 Accepted: 17-03-2018

(iD) http://orcid.org/0000-0002-4464-5009
}

DOI: http://doi.org/10.4038/sljs.v36i1.8474

\section{Conclusion}

Waiting time for elective urological surgery is too long though waiting time for malignancies is satisfactory in the unit. Socioeconomic status of the patient has no statistically significant influence on the waiting time indicating equity in the unit policy.

\section{Introduction}

Surgery is a fundamental modality of providing health care to people. Conditions that are treated primarily or frequently by surgery, constitute a significant portion of the global burden of disease. However, 5 billion people in the world do not have access to safe, affordable surgical care when needed [1]. Therefore in 2015, World Health Association passed a resolution to strengthen emergency and essential surgical care and anaesthesia as a component of universal health coverage [2]. One of the core indicators of monitoring universal access to safe, affordable surgical care is access to essential surgery [1]. With many competing health priorities and significant financial constraints, surgical services in low and middle income countries (LMIC) are given low priority within national health plans and are allocated few resources from domiciliary accounts or international development programmes [3].

Sri Lankan health care system is considered as a model where low investment has produced remarkable achievements in health indicators related to maternal and child health $[4,5]$. However, the quality of surgical services in Sri Lanka has not been evaluated in depth and no data is available in this regard. This is important as researchers lament that there are hiatuses and weak areas in the health system of Sri Lanka [6, 7]. With the expansion of the private health care system in the country, a significant portion of health services is provided by private health institutes. The private out-of-pocket health expenditure of households in 2009 was about $45 \%$ of total health expenditure [8]. Although certain health care services in the private sector may be accessible to many Sri Lankans, surgical services are expensive and beyond the means of the majority of Sri Lankan population. The per capita GDP for Sri Lankans in 2014 was only SLR 169609 and the average monthly household income in 2013 was SLR 45 878, which makes surgical operations in private institutions not afford- 
able to the majority [9]. Furthermore, private institutions which provide major surgical services are confined to major cities of the country making physical access a difficulty [10].

Analysing the waiting time for operations is one way to determine access to surgical services in a health system. Even the political manifesto of one of the candidates of the 2015 presidential elections who was to be the winner subsequently, promised to reduce the waiting period for surgical services in Sri Lanka [11]. In 2017 the Director General of Health Services of Sri Lanka issued a circular announcing the need to audit waiting time for key operations in all state funded hospitals [12]. This clearly illustrates the importance and relevance of this topic though not identified in depth so far in research studies. Another issue that plague the Sri Lankan health system is inappropriate manipulation of the waiting list by influential third parties i.e. staff members of the institute to fast track patients known to them. This leads to repeated cancellation of patients who deserve surgery but who do not have appropriate contacts. This may result in surgical services not being delivered to many of those who need them the most and threatens the equity of health services provision across the country.

The main objective of our study was to determine access to surgical services in a urology unit of Sri Lanka by calculating the average waiting time for different urological operations and to determine whether there is a significant difference in the waiting time between different income categories and social classes. It is also intended to assess if there is a statistical difference in waiting time for cancer patients versus non cancer patients.

\section{Method}

This was a prospective exploratory study conducted at the urology unit in Colombo South Teaching Hospital Kalubowila from 1st of January 2016 to 30th of April 2017. All patients who were admitted to undergo elective urological surgery were recruited for the study. The surgical operations were categorised according to BUPA (British United Provident Association) classification [13].

Patients who underwent emergency surgery and minor surgery according to the BUPA classification were excluded from the study. Number of days between the decision for surgery was taken and day the surgery was performed considered as the waiting time. Transurethral resection of the prostate gland (TURP) and open pyelolithotomy for staghorn calculi were selected respectively as the index operations to calculate the waiting time among endoscopic and open surgical procedures for non-malignant conditions. The waiting time for surgeries performed for all malignant conditions were analysed irrespective of the type and complexity of the operation.
Data collection was done using a pretested data collection sheet which contained patient demographic details, the surgery, waiting time, income category, if they receive Samurdhi allowance or not, number of postponements and the reason for it. The income groups and social classes were categorised using the data available in Household Income and Expenditure Survey 2012/2013 conducted by the Department of Census and Statistics [14]. Data collection was done by trained medical officers attached to the unit during patient's admission to the ward for surgery.

Data analysis was done by SPSS (Statistical Package for the Social Sciences) version 20. Kaplan Meier survival analysis was performed with Log Rank test. Approval for the study was obtained from the Ethics Review Committee of the Institute.

\section{Results}

There were 1759 surgical operations performed during the study period of 16 months. One thousand and eighty four patients were admitted to undergo elective major and intermediate surgeries and were eligible to be included in the study sample. Five data sheets were discarded due to incomplete data. Finally, 1079 cases were selected for the analysis.

There were $845(78.3 \%)$ men. The male to female ratio was 3.6:1. Eight hundred and fifty five patients $(79.2 \%)$ were from the western province, where the hospital was situated (Table 1). The mean age of the study population was 54.4 years (range 10 to 88 years). Eighty nine patients (8.2\%) were Samurdhi beneficiaries. Two hundred and nineteen (20.3\%) surgeries were performed for malignancies.

Distribution of patients according to the monthly household income is given in Table 2. Majority of patients $(42.5 \%)$ had a monthly income between SLR 16000 and 30000 while 285 patients $(26.4 \%)$ had an income below SLR 15000 per month. Most of the operations ( $\mathrm{n}=909,84.2 \%$ ) were performed without any postponement although fifty one $(5 \%)$ operations were postponed twice or more (Table 3 ).

Table 1. Distribution of patients according to the province of residence

\begin{tabular}{|l|r|}
\hline Province & Number (\%) \\
\hline Western & $855(79.3)$ \\
\hline Southern & $98(9.1)$ \\
\hline Wayamba & $26(2.4)$ \\
\hline Sabaragamuwa & $39(3.6)$ \\
\hline Central & $13(1.2)$ \\
\hline Uva & $15(1.4)$ \\
\hline North Central & $15(1.4)$ \\
\hline Northern & $10(0.9)$ \\
\hline Eastern & $8(0.7)$ \\
\hline Total & $1079(100)$ \\
\hline
\end{tabular}


Table 2. Distribution according to the monthly household income

\begin{tabular}{|l|r|r|}
\hline $\begin{array}{c}\text { Monthly income } \\
\text { (SLR) }\end{array}$ & Number (\%) & $\begin{array}{c}\text { Median waiting } \\
\text { time (days) }\end{array}$ \\
\hline$<15000$ & $285(26.4)$ & 40 \\
\hline $16000-30000$ & $457(42.5)$ & 43 \\
\hline $31000-50000$ & $234(21.7)$ & 36.5 \\
\hline$>51000$ & $103(9.4)$ & 30 \\
\hline Total & $1079(100)$ & 40 \\
\hline
\end{tabular}

Table 3. Frequency of cancellation of operations

\begin{tabular}{|c|r|}
\hline Number of times & \multicolumn{1}{|c|}{ Number (\%) } \\
\hline 0 & $909(84.2)$ \\
\hline 1 & $119(11)$ \\
\hline 2 & $37(3.4)$ \\
\hline 3 & $12(1.2)$ \\
\hline 4 & $2(0.2)$ \\
\hline Total & $1079(100)$ \\
\hline
\end{tabular}

The median waiting time for all surgeries was 40 days (Table 2 ). The median waiting time for malignancies was 20 days compared to 48 days for non-malignancies $(\mathrm{p}=0.0001)$. The median waiting time for 82 cases of TURP was 55 days. Fifty nine patients who had open surgery for staghorn calculi had a median waiting time of 125 days.

The median waiting time according to the income category varied from 30 days to 43 days (Table 2). There was no statistically significant difference across different income categories, with regard to the waiting time $(p=0.38)$. The relevant survival curve is shown in figure 1 .

The median waiting time for patients receiving Samurdhi beneficiary was 48 days and 40 days for those who do not receiving it. There was no statistically significant difference between these two groups $(\mathrm{p}=0.29)$. The relevant survival curve is shown in figure 2 .

\section{Discussion}

According to the Health Survey 2011 of the Ministry of Health of Sri Lanka, there were 437 operating theatre tables in the country and 933331 surgical operations were carried out during the year in Sri Lanka [15]. Out of this, 305573 were major operations. Despite these large numbers, there are long waiting lists for surgical operations in the state funded health care institutes of Sri Lanka. Long waiting times may be due to shortage of resources (surgical beds, lack of medical equipment), lack of operating room time, short staffing or inefficiencies in the organisation of services. Sometimes it may be due to inappropriate overuse of medical services [16]. Excessive waiting times may lead to adverse health effects such as stress, anxiety and morbidity related to the index illness [17]. It may cause patient dissatisfaction and strained patient-doctor relationships and damage the public

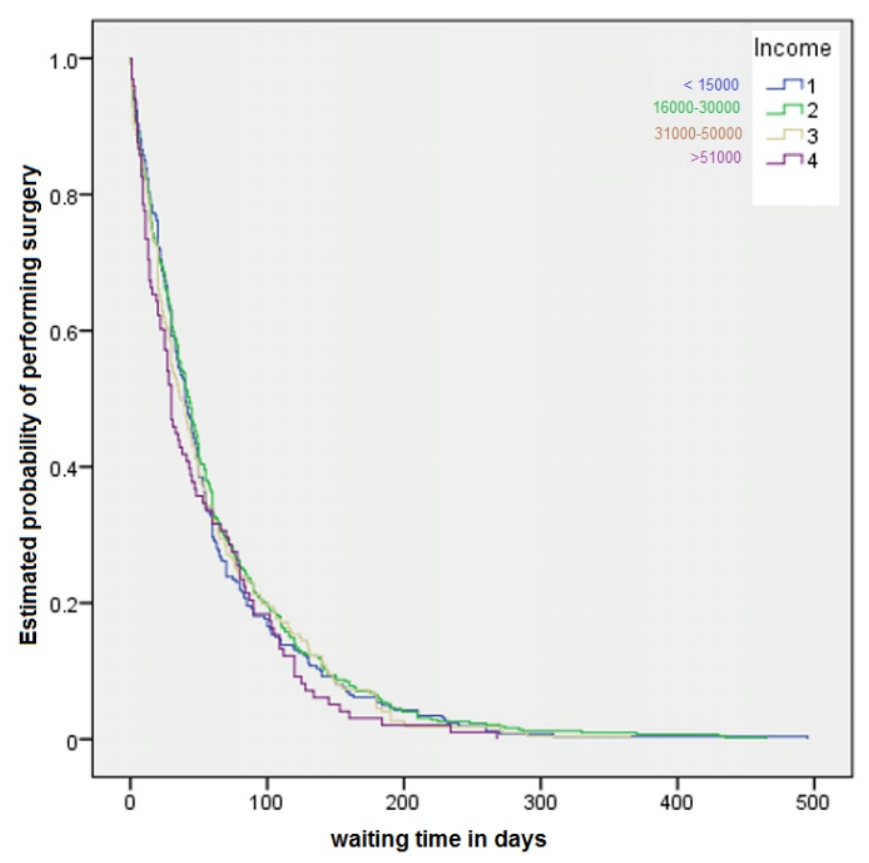

Figure 1. Survival curve showing the estimated probability of performing surgery and the waiting time of the different income groups

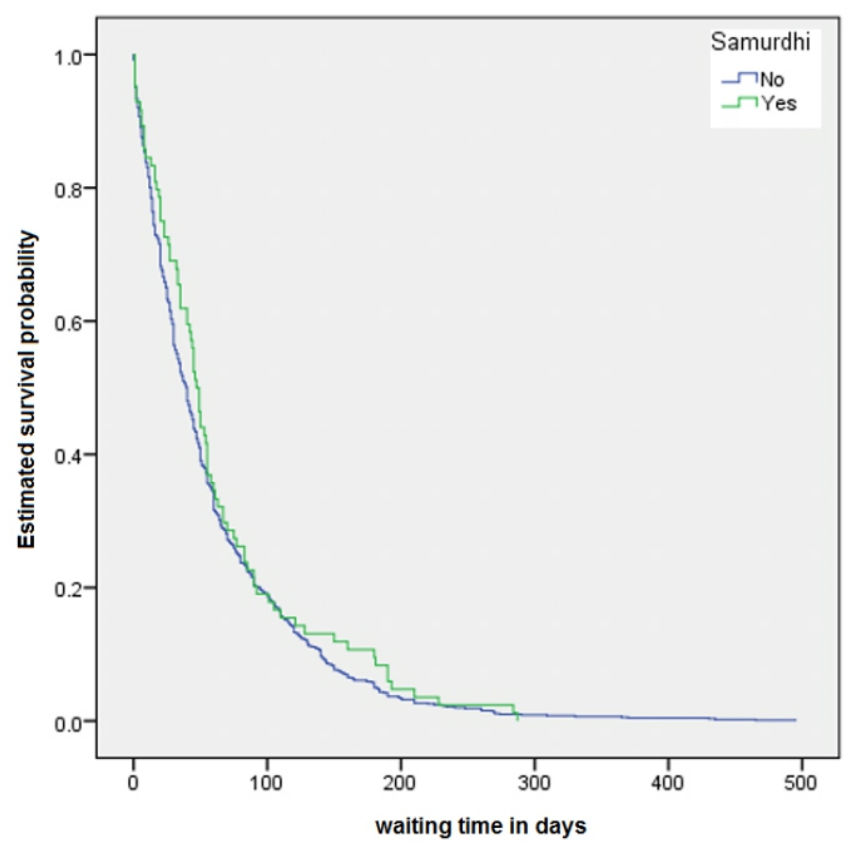

Figure 2. Survival curve showing the estimated survival probability and the waiting time of the recepients and nonrecepients of Samurdhi

perception on the health system. The median waiting time for TURP and renal stone surgery were 55 days and 125 days respectively, which could be considered too long and unsatisfactory as most patients who had TURP were having indwelling urethral catheters and patients with staghorn calculi were symptomatic. One way to rectify this would be to build and equip more regional urology units of the country.

In lower income countries and many middle income 
countries, access to safe and optimal surgical services for cancer is poor [18]. The median waiting time for malignancies in our study cohort is 20 days. According to the handbook for NHS constitution of UK in 2013, a maximum one month wait is allowed from the date a decision to treat is made to the first definitive treatment for all cancers [19]. We have managed to achieve this target of a developed country despite a heavy case load and limited resources. The bed strength of the male urology ward of Colombo South Teaching Hospital is seven and there is no dedicated female ward for urology.

There is no statistically significant association among different income groups and the waiting time for surgery $(\mathrm{p}=0.38)$ (Table 2). Also, the waiting time for surgeries between Samurdhi beneficiaries and those who do not receive Samurdhi remained statistically insignificant $(\mathrm{p}=0.29)$. This indicates that the patients' socioeconomic status hasn't had an impact on allocation of dates for surgery, which reflects fair practice appreciating social norms of equity.

The cancellations and postponement rate of elective surgery was $15.8 \%$ (approximately 1 in 6 cases). Considering the number of non-minor surgeries performed per day and the number of operating theatre sessions during the study period, it can be assumed that approximately one case is postponed for each list. Although a detailed analysis of reasons for postponement was not done in this study, the causes encountered can be broadly categorised as patient related factors and institute related factors. The common institute related factors were lack of operating time and trade union action by health care workers across all categories. Common patient related factors were inability to turn up on the given date due to various health related and family issues. We need to evaluate this issue in depth and aim at minimising the cancellations further which will enhance the quality of the services in the unit.

Manipulation of waiting periods by patients who are known to staff members of the hospitals and Department of Health is a well-known nuisance in Sri Lankan health care delivery institutes. Even socioeconomic status has been found to induce bias in waiting time [20]. This may result in certain vulnerable and neglected population groups facing the biggest impact posing a threat to the concept of equity in surgical care to all communities. Economically disadvantaged families with a very low income in Sri Lanka are given a monthly stipend called the Samurdhi allowance by the government. According to the results of our study, even the Samurdhi recipients had a waiting time similar to NonSamurdhi recipients. The percentage of Samurdhi recipients in our study sample $(8.2 \%)$ was similar to the proportion of Samurdhi recipients in Colombo district (9\%), indicating that the urology unit of Colombo South Teaching Hospital caters to a true cross section of the Sri Lankan society while maintaining equity.
In 2007, the Ministry of Health launched a 10 year Health Master Plan. Enhancing quality of service delivery and improving health status of vulnerable populations are two of the eight immediate objectives to be met [9]. It is important to develop models to easily identify deficiencies in the existing system so that corrective measures can be taken to increase the equity of service provision. To achieve optimal resource utilization and enhanced equitable resource distribution for equitable health care service provision, it is essential to identify the existing situation of resource distribution and performance of health system.

Research on health policy and systems such as implementation research is crucial to make what is possible in theory, a reality in practice $[21,22]$. Such research studies would describe the real world's context and factors that are either overlooked or not captured by other research disciplines. The results of our study describe the real world scenario in providing uro-surgical services in Sri Lanka. Therefore, Sri Lankan health policy makers should strive to build adequate capacity to meet the current and future needs. This entails significant capital investment in uro-surgical infrastructure and equipment in order to upgrade existing urology units and to establish new units in regional hospitals, which already have trained urological surgeons, whose skills are been underutilised. Furthermore, this model we have used to determine access to uro-surgical services can be used to assess future performance evaluations and determine trend analysis in surgical units throughout the country. Performance evaluation needs to be carried out so that incentives and rewards are attributed accordingly. This would improve the efficiency of the existing health care delivery system using the already available resources.

In this study, the waiting time was calculated among patients who were admitted for surgery. There is a remote possibility that few of the scheduled patients may have undergone surgery elsewhere (drop outs) or may have even died due to their illness or for any other reason. Failure to address this censored data (deaths and drop outs) for the waiting time calculation remains a limitation of this study. However, in real time clinical practice these numbers would be negligible and unlikely to influence findings significantly.

\section{Conclusion}

Waiting time for TURP and renal stone surgery in the urology unit of Colombo South Teaching Hospital, Sri Lanka appears to be too long though waiting time for operations for malignancies is on par with the standards and targets in the UK. Socioeconomic status of the patient has no statistically significant influence on the waiting time, indicating equity in the unit policy. The model described in this study can be used by the Department of Health of Sri Lanka to assess access to services in surgical units of the country. 
All authors disclose no conflict of interest. The study was conducted in accordance with the ethical standards of the relevant institutional or national ethics committee and the Helsinki Declaration of 1975 , as revised in 2000 .

\section{References}

1. Mock CN, Donkor P, Gawande A, Jamison DT, Kruk ME, Debas HT. Essential surgery: key messages. In Essential Surgery: Disease Control Priorities 3rd edition (Volume 1). Washington DC: The International Bank for Reconstruction and Development/ The World bank; 2015 Nov. Chapter 1

https://doi.org/10.1596/978-1-4648-0346-8 ch1

2. World Health Association (WHA) resolutions, 2015 May

3. Dare AJ, Anderson BO, Sullivan R, et al. Surgical services for cancer care. In Cancer: Disease Control Priorities edited by Gelband H, Jha P, Sankaranarayanan R and Horton S. 3rd edition (Volume 3). Washington DC: The International Bank for Reconstruction and Development/ The World bank. 2015; Chapter 13

https://doi.org/10.1596/978-1-4648-0349-9_ch13

4. World Health Statistics 2014, World Health Organization, 2015

5. Jayasinghe Saroj. Narrowing health inequalities in Sri Lanka: issues and challenges. Ceylon Med J2010; 55:73-6.

https://doi.org/10.4038/cmj.v55i3.2289

6. Abeygunasekera Anuruddha M, Wijayarathna Suranga N, de Silva Kusal, Gobi Upayasekeram, Suvendran Swarna, Weerasinghe Sujeeva. Clinicopathological characteristics and primary treatment of prostate cancer in a urology unit of Sri Lanka. J Can Res Ther 2015; 11: 780-5 https://doi.org/10.4103/0973-1482.140839

7. Abeygunasekera AM. Beyond Evidence-based Medicine: Need for a new paradigm in patient care delivery. Education for Health $2004 ; 27$

https://dx.doi.org/10.4038/sljs.v32i2.7364

8. Dayaratne GD. Private hospital health care delivery in Sri Lanka: Some issues on equity, fairness and regulation. Institute of Policy Studies of Sri Lanka, Colombo 2013

9. Sri Lanka state of the economy 2015, Institute of Policy Studies of Sri Lanka, 2015

10.Govindaraj R. Health care in Sri Lanka. What can the private health sector offer? Health, Nutrition and Population (HNP) Discussion Paper, World Bank Human Development Network, 2014
11. Hundred day programme. Presidential election manifesto of Maithripala Sirisena New Democratic Front 2015, item 44

12.Jayasundara Bandara JMW. Implementation of clinical Indicators to assess the quality of care. Ministry of Health, Nutrition \& Indigenous Medicine. Circular No: 01-07/ 2017 issued on 05.01.2017

http://www.health.gov.lk/CMS/cmsmoh1/viewamendment.php? cno $=01-07 / 2017(2) \&$ med $=$ english

13.Limited BI. Urological Procedures, BUPA Schedule of Procedures 2014; 68

http://www.upperlimb.org/app/uploads/2014/05/Schedule-of procedures-14_04_2014.pdf

14. Household Income and Expenditure Survey 2012/ 2013, Department of Census and Statistics - Sri Lanka, 2014

15. Health Facility Survey 2011: District Profiles, Ministry of Health, Sri Lanka, 2011

16. Brownlee S, Chalkidou K, Doust J, Elshaug AG, Glasziou P, et al. Evidence for overuse of medical services around the world. Lancet 2017; 390: 156-68 https://doi.org/10.1016/S0140-6736(16)32585-5

17. Ally M, Lee T, Ecclestone H, Teo L, Kavia R. Malignant features of a benign waiting list. J Clin Urol 2017; 10:105-9. https://doi.org/10.1177/2051415816671041

18. Funk LM, Weiser TG, Berry WR, Lipsitz SR, Merry AF, Enright $\mathrm{AC}$, et al. Global operating theatre distribution and pulse oximetry supply: an estimation from reported data. Lancet 2010;376:1055-61 https://doi.org/10.1016/S0140-6736(10)60392-3

19. Delivering cancer waiting times; A Good Practice Guide https://www.england.nhs.uk/wpcontent/uploads/2015/03/deliver ing-cancer-wait-times.pdf

20. Nymo LS, Aabakkn L, Lansen K. Prority and prejudice; does low socioeconomic status bias waiting time for endoscopy? A

blinded, randomised survey. Scand J Gastroenterology 2017; 16:1-5 https://doi.org/10.1080/00365521.2017.1402207

21.Peters David H, Tran Nhan T, Adam Taghreed. Implementation research in health: a practical guide. Alliance for Health Policy and Systems Research, World Health Organisation, 2013

22. Raj S, Kirtania J. Waiting time of inpatients before elective surgical procedures at a state government teaching hospital in India. Indian J Public Health 2017; 61: 284-9 https://doi.org/10.4103/ijph.IJPH_210_16 